\title{
The Ethnography Approaches on Digital Banner Culture in Tamil Nadu, India
}

\author{
Dr. M. Suresh ${ }^{1^{*}}$, Dr. V. Ratnamala ${ }^{2}$ \\ ${ }^{1}$ Assistant Professor, Department of Journalism and Mass Communication, St.Joseph University, Dimapur, \\ Nagaland, India \\ ${ }^{2}$ Associate Professor, Department of Journalism and Mass Communication, Mizoram University, Mizoram, \\ India
}

*Corresponding Author: Dr. M. Suresh, Assistant Professor, Department of Journalism and Mass Communication, St.Joseph University, Dimapur, Nagaland, India

\begin{abstract}
This article explores the definition of digital banner and how this is differences from posters, murals and other visual images. This article mainly discussed about how digital banners are designed and that banners are designed according to the customers' choices and needs. This study has been found the nature and working of digital banner studios in Tamil Nadu. This study has deals with the rules and regulations followed by the designers and digital banner users. It will also explain how the digital banners become a good marketing tool and how much this culture has created job opportunities to the people over the Tamil Nadu. The researcher has utilized qualitative research methodology for this study and used ethnography research methods of data collection. The researcher has gone his filed areas in Madurai, Tirunelveli and Chennai for data collection in Tamil Nadu. The present study discussed with how the banners are used for their home functions, like (how people constructed their images and how their created their banners). In this study has probe in to who are the castes people can display their banners in local place and to be analyzed on the semiotic perception in this study. the course of the events on the Palestinian issue got the highest rank with an average of $(67.4 \%)$.
\end{abstract}

Keywords: Street Media, Caste, Visual Ethnography, Digital Banners, Popular Culture

\section{INTRODUCTION}

Tamil Nadu's public space is dotted with images in various shapes, sizes and genres displaying a blown up imagery of the state's main political leaders and movie stars. This culture of display is an evidence of the long-standing intimate relationship between the region's film industry and its political parties. Most actors and others working in the state's movie industry have pursued political careers in the state. These images have been central to the political process in which populist, person- centered politics has shaped a particular caste of long-ruling politicians, whose personality is also central to politics, and the images produced by the party workers contribute to the image as well as the production of political leaders in Tamil Nadu.

This article has explores how digital banner is medium and how it's differences from posters, murals and other visual images in communication. The main objective of this article has given definition of the Digital banners, digital banners is one of the important thing is on all functions and other occasions in Tamil Nadu. Besides, the study discusses how digital banners were designed and that banners are designed according to the customers' choices and needs. This study has been found the nature and working of digital banner studios culture in Tamil Nadu. This study has deals with the rules and regulations followed by the designers and digital banner users. It will also explain how the digital banners become a good marketing tool and how much this culture has created job opportunities to the people over the Tamil Nadu.

\section{BRIEF HISTORY OF BANNER CULTURE IN TAMIL NADU}

The study has to begin with few prior studies for understanding of this banner culture. A book written by Jacob Preminda: 2010 Celluloid Deities: The Visual Culture of Cinema and Politics in South Indiais a detailed work about Banners, Cutouts and artists' lifes in Tamil Nadu. According to him, 
during 1990s, the banners were hand painted by artists. During 1980-2000, the banners were commisioned only be film producers, film distributors, theatre owners and politicians. The banners were used for film publicity and political campaigns. Banners production in Chennai was a highly viable industry during the 1990s. Most of the artists, letter painters and carpenters belonged to the city's banner artist union (Ovium Munnetra Sangam- Progressive Artists' Association) comprising of 150 members in Chennai (Preminda, 2010).

All artists in this business were all male because of the nature of the work - long standing hours, tiresome physical activity and working late night; the job is not considered to be appropriate for females. It was rare to find women in Tamil Nadu as banner artists. In 1990, banners were produced in workshop studios by teams' of artists, apprentice and carpenters. Once the artists complete their work, group of laborers transported the items at night from the open-air by banner company studios to mount them on wooden framework that they had erected along major streets, beside buildings, outside cinema theaters and in other public places. Cinema banners were displayed for the whole premier of the film, usually between two weeks and three months while commissioned by political parties were on display for just two or five days, the duration of a political meetings or rally. Plywood cutouts were turned into fire wood and the banners painted on canvas became tarpaulins that covered the huts of slum dwellers. In any case, the close association of the banner medium with the culture of entertainment cinema and the overtly commercial or propagandistic content of the images raised doubts about their validity as an art form. The manually painted banners saw a downfall after the year 2000 which saw emerge of digital banners in Tamil Nadu. The popularity of the digital banners caused unemployment problem to many artists' as their work was easily substituted by computer designing software like Adobe Photoshop and Coral Draw (Preminda, 2010). After the advent of digital banner, societies have been changing politically and culturally in Tamil Nadu.

\section{DEFINITION OF DIGITAL BANNERS}

One of the real challenges to define what is digital? According to Cambridge dictionary, the word digital has three meanings.

- Recording or storing information as series of the numbers 1 and 0 , to show that a signal is present or absent

- Using or relating to digital signals and computer technology

- Showing information in the form of an electronic image

For the digital banners, the second meaning is very appropriate. Here the banners are created using computer technology. Here the banners are related to computer technology.

As per Merriam Webster dictionary, the word digital has number of meanings. But the suitable meaning for the word digital in the context of digital banner is, electronic as it is characterized by electronic and especially computer technology.

Even the definition for digital divide is that an economic and social inequality with regard to access to, use of, or impact of information and communication technology. Here the digital refers to the information and communication technology. So it is very suitable to refer digital to computer technology.

The digital technology has made human life as easy and simple. Computer is one of the digital tools and it's making our life simple and fast with the help of the digital technologies. For Example, the music is of the good example, how is it? One decade before songs are composed by the real instruments but now most of the songs composed with help of digital instruments.

The flex banners are made by hand painted artists and now the digital banners are made by the digital technologies and software. The banner can be flag or other piece of cloth bearing a symbol, logo, slogan or other message. The banner often refers to a long sign that is announcing or advertising something. The banner as ceiling and announcing in sparkly letters, images, colors, and etc., the banner is called as placard, poster and notice (Margaret Rouse, 2010).

Flex banner designers first emerged in metropolitan cities like Chennai, Madurai and Coimbatore and after 2008 this culture got disseminated everywhere throughout Tamil Nadu. Colloquially the digital banners are also called as flex banners. The flex banner is flexible to hang anywhere thus it is called 
flex banner but after a few years later, people started calling it as a digital banners. Using digital technology i.e computer and its software, one can make digital banner in a short span of time. We can print many different size of banner which range from $3 * 3$ to $10 * 100$ (Ten meter height and hundred meter feet). This is possible because of digital technology and eventually people called it digital banner which in Tamil means (எண்ணியல்பதாகை). The people used focus lights and other decorations for their digital banners in cities and villages. The Digital banners are made in digital studios where the photos are edited; banners are designed, produced and printed all under one roof.

So the digital banner is the combination of two words. They are digital and banners. Here digital refers to the digital technology and banner refers to a long sign that is announcing or advertising something. So we can define digital banners as digitally made banners for publicity purpose.

When people organize any Social services, Political campaigns, Protest and any other programs we can see numerous banners; small size to mega size of banners in Tamil Nadu. Mostly, important names, programs titles and other details are shown in banners. In Tamil Nadu, political leaders' images and political symbols are shown in the banners then party workers hold that banner roaming to entire cities with those banners for campaigns. So that symbols will touch more people's mind and they used banner as tool to reach common people. In the year of 2000, out-door Advertisements are mostly put up as a mega size digital banner and erected cinema heroes images in Mumbai. Those digital banners have mass attentions among publics, thus every company wanted to display their own digital banners for marketing purpose. Later in 2002 at Madurai, Kamal Hashan ${ }^{1}$ fans went to Mumbai for making flex banners for PammalK.Sambandan (2002) movie releases. They set forth Kamal Hashan picture from a movie and wrote his name in that banner. After seeing the banners in Madurai, some rich business man wanted the same size banner and they went to Mumbai for printing their banners. Then, few months later flex banner culture is undertaken by the politicians for their political campaigns while in early days politicians used poster and cut-out for their campaign in Tamil Nadu.

\section{Methods of Data Collection}

Qualitative research techniques like observation, intensive interviews, analysis of existing documents, photography and films was used to collect primary data from the area of study. Collection of primary data: Intensive interviews with key informants or interlocutors from the members of fan clubs, digital banner designers, digital banner customers, digital banner consumers\& members from different localities. The photographs are used as a visual ethnography tool in this study. This technique is adopted from the study of RekhaS.Murthy on street media. The secondary data was collected from the published books, news articles, journals, and unpublished works (Murthy, 2005). The photograph of the digital banners was collected during data collection and of analyzed. According to Caldarola, the photographic research method is derived largely from a particular epistemological conception of photographic representation, which may be summarized by following premises: 1) that photographic images are event- specific representation, 2) that their relevance or meaning is dependent upon the context of the image producing event, 3) that the imaging event is socially interactive and communicative process that involves the mutual understanding and participation of both the observer and the observed. The nature of the observation process follows as a direct consequence of this epistemological framework.

\subsection{Digital Banner Culture in Tamil Nadu}

The major difference between the hand painted banner culture and digital banner culture is that here the common man started using the digital banners for his own publicity. The digital banner is one of the most important visual media in Tamil Nadu. It can be considered as street media as the streets of Tamil Nadu is flooded with digital banners. These digital banners have become the part and parcel of Tamil culture. Whenever there is any celebration, the people used to have their own digital banners. Here celebration includes marriages, house warming ceremonies, village temple festivals, Pongal ${ }^{2}$, puberty functions and many. So the researcher has mapped out the celebrations in the areas of Madurai and Tirunelveli for which they use to print digital banners.

\footnotetext{
${ }^{1} \mathrm{He}$ is a Tamil and Indian film actor, Film maker, lyricist, producer and he has many fan clubs in Tamil Nadu, India.

${ }^{2}$ The Pongal festival is very famous in Tamil Nadu. The Pongal also referred to as "Harvest Festival", is observed by the people of Tamil Nadu, located in the Southern part of India. The idea behind celebrating this day is the gratification of people towards "God Sun", for bringing about the season of harvest, which is a boon for them, The festival is celebrated on $15^{\text {th }}$ January every in Tamil Nadu.
} 


\subsection{IllaVizha (Home Function)}

IllaVizha is a function celebrated by Thevar community in and around Madurai village, Tamil Nadu. The organizer of the function may not have any other occasions of celebrations to get back the money which he has already given as gift to his relatives and friends celebrations. This is a kind of money mobilizing function and here the relatives and friends pay back their share of money for the organizer. It is a great example for social capital. On the day of IllaVizha, the host offers a feast to the guests. In this function no rituals are done. The host provides food and some memorable gifts for their friends and relatives. For IllaVizha, the hosts erect a banner displaying their family photos, occupations symbols, political identity and religious identity in their digital banners. IllaVizha digital banners have symbols that welcome every individual who attend the function. The digital banners are usually displayed in front of the function hall or homes.

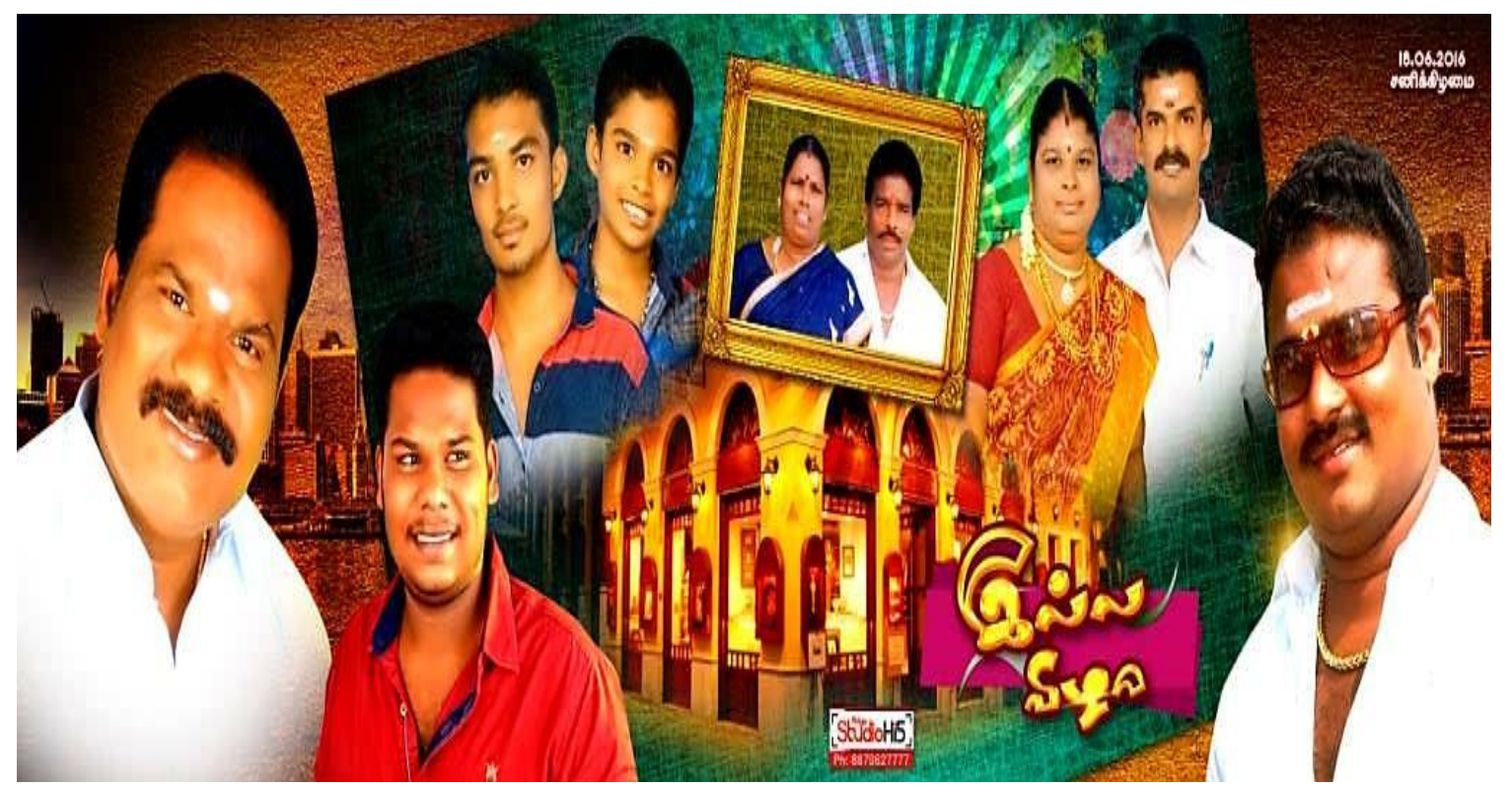

Figure1: The Banner designed for IllaVizha in Madurai

\subsection{Moi Vizha (Gifted Some Money)}

MoiVizha is one of the most famous functions in Madurai villages. This function is organized once a year. MoiVizha is money oriented program where the host collects money from close relatives and friends as a gift. In some regions of Tamil Nadu, people have one practice where a family host a function and invites his relatives and friends. This function is normally used for the mobilizing capital of the host family. Nevertheless, IllaVizha and MoiVizha have a same concept but they are celebrated in different names. MoiVizha is very popular among the Mukkulathor ${ }^{3}$ community of Madurai region. For MoiVizha also, they used to put up digital banners welcoming their guests.

\subsection{Ear piercing ceremony (KaathaniVizha)}

Ear piercing ceremony is celebrated by all community in Tamil Nadu. It is a common ceremony but Thevar community gives major importance to this function. This is nothing but the first birthday celebrations of kids. In Tamil Nadu, when a kid completes a year of birth, then only they used to pierce the ear so that they can wear the ear rings. It is an important ritual for the kid. This ceremony is based on Brother - Sister Relationship. Here the maternal uncle (Thai mama) is the most vital person on this day and his sister will get more recognition and respect based on the contribution in the celebration in the nature of gold and money. Also there is ritual that, the kid would be placed on the lap of maternal uncle and ear piercing ceremony happens. In this function the maternal uncle is incharge of the banners where he designs the banner with his nieces, nephews and other relatives. It used to be displayed on road sides, main streets and bus stops.

\footnotetext{
${ }^{3}$ Mukkulathors, also known as Thevar and including three ethnic communities Kallar, Maravar and Agamudaiyar castes constitute the Mukkulathor which means the people of three castes. (S.Kadhirvel, A History of the Maravars, Madurai, 1977, p. 14.)
} 


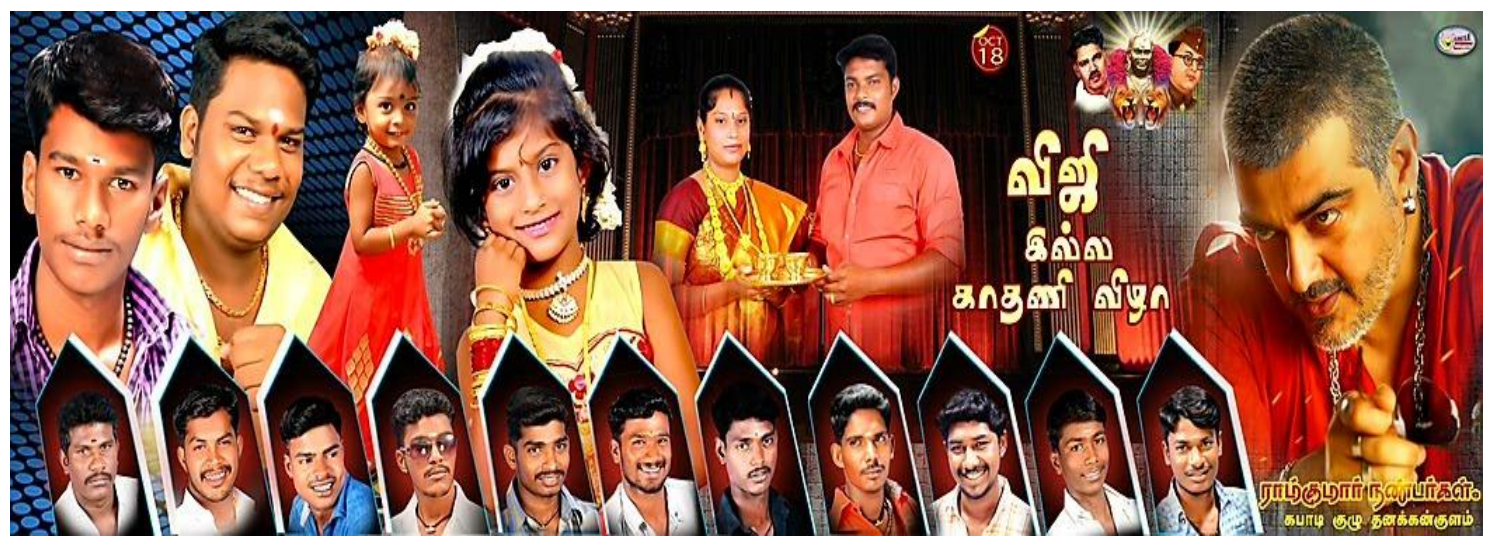

Figure2: The banner designed Ear piercing ceremony (KaathaniVizha) in ThanakkanKulam, Madurai

\subsection{Housewarming ceremony (PuthumanaiPuguVizha)}

Housewarming ceremony is a ceremony traditionally held soon after building a house and moving into that new residence. It is an occasion for the host to invite close relatives and friends to visit their new house. On this day, house owner or the host will invite his close relatives and friends and give them a grand feast. So for this house warming ceremony also, few people used to keep banner for the function.

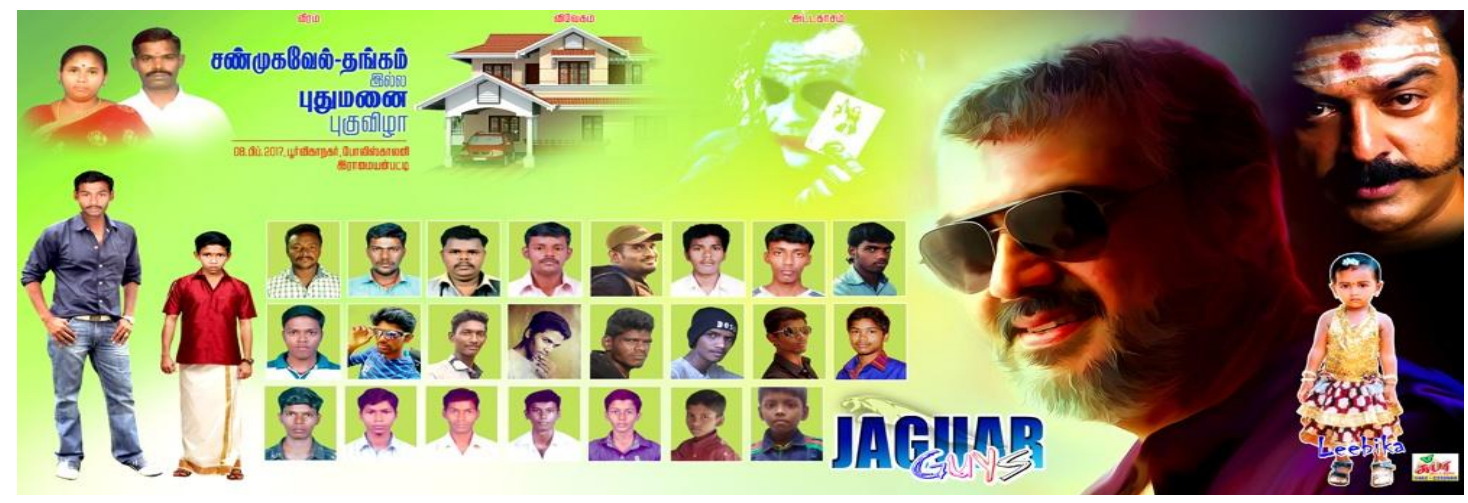

Figure3: The banner designed for Housewarming ceremony, Tirunelveli.

\subsection{Puberty ceremony (Poopunitha NeerattuVizha)}

Puberty ceremony is celebrated for girls when they get their first periods. Puberty ceremony publicizes the sexual maturity of the girls and in a way it's denotation of matrimonial availability. When the girl gets her first period, it is celebrated with many rituals in South India, particularly Tamil Nadu. Usually it is celebrated for 16 days and the girl is isolated and considered as impure. It also reflects the cultural taboos of menstruation. On the $16^{\text {th }}$ day, the isolation is over and there will be a huge ceremony. In Tamil Nadu, this function is celebrated lavishly; few people very conservatively celebrate this function to disclose the coming of age. In this ceremony too, the maternal uncle is given importance as he has to participate in many rituals and he also expected to gift gold, money and food items. So for the puberty ceremony too, they used to keep digital banners for welcoming the guests in front of their homes and halls.

\subsection{Wedding Function}

The wedding is one of the significant celebrations in Tamil Nadu. The digital banners are displayed everywhere in their village. All the communities used to display many banners for weddings. Normally when the dates for marriage get fixed, the friends of bridegroom used to plan for making digital banners. They will start arranging special photo shoot and select the best photographs for the digital banners. Before two days of the wedding function, the bridegroom and his friends used to assemble in the digital banner studio and participate in the designing process. They will give their demands and suggestions to the designer and the designer used to design the digital banner according to the customer's satisfaction. They used to design at least three to four digital banners with the images of bride, bridegroom and the groom's friends. They also used to give decorative catchy slogans for the digital banners. 


\subsection{Temple festival}

Local festivals and village temple festivals are part and parcel of Tamil culture. Temple festival i.e Kovil Thiruvizha or Kovilkodaivizha is celebrated very pompously in Tamil Nadu. Madurai is known as city of celebrations. Chithirai Thiruvizha is celebrated annually in the month of April in Madurai. It is celebrated during the Tamil month of Chithirai. It used to be celebrated for the whole month. The temples in the rural areas used to have their annual celebration. It is called as Temple festival. For these celebrations also, the youth used to design digital banners. The digital banner used to have images of the god, goddess and the youth of the locality.

\subsection{Fan clubs}

The people of Tamil Nadu are mostly film buffs. Tamil films are intertwined with the socio cultural political life in Tamil Nadu. Tamil Nadu is also known for its fan clubs and film cult culture. Digital banners are designed for every new movie premier by the movie makers. But, apart from these banners, the fans make their own digital banners. They used to reconstruct their own version of the banner with the heroes of the movies and place their own pictures in the banners next to the pictures of the movie stars. This is prepared from their own expenses and is mainly done to showcase their creativity and for self-publicity. There can be as many as hundred different versions of banner created by fans displayed in different parts of the city around the theaters, crowded places and in open spaces. The banners are made in good quality sheets and designed meticulously.

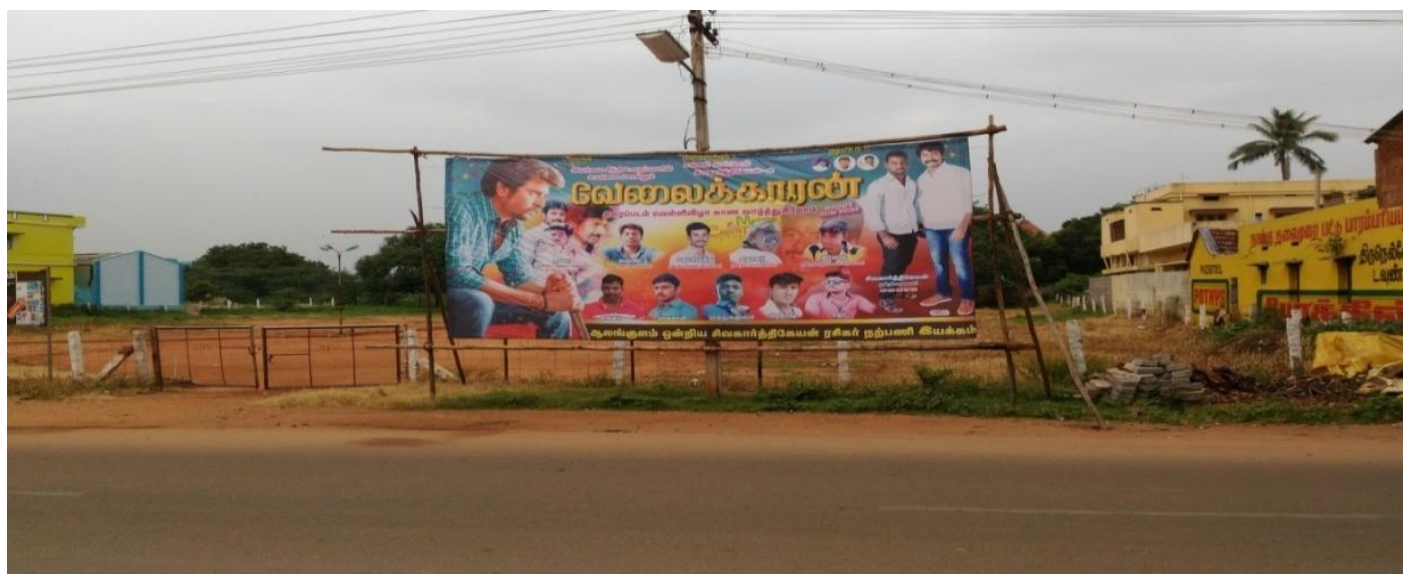

Figure4: Fan Culp members are designed their banner and displayed in front of theatres.

The fans and fan clubs used to celebrate the birthday of their favorite film stars and also used to express their support to the release of their favorite film star's new film. The fan club of Vijay displayed 120 digital banners in Tirunelveli to celebrate the release of a new Tamil movie. One can see the mega size digital banners in the various localities of Madurai and Tirunelveli on the birthday of various film stars including Rajinikanth, Kamal Hasan, Ajith and Vijay. Below is the banner displayed for Tamil actor Vijay's birth day celebration. It was found displayed on his birthday i.e June $22^{\text {nd. }}$. The fan club members had given slogan calling Vijay the Future Chief Minister of Tamil Nadu.

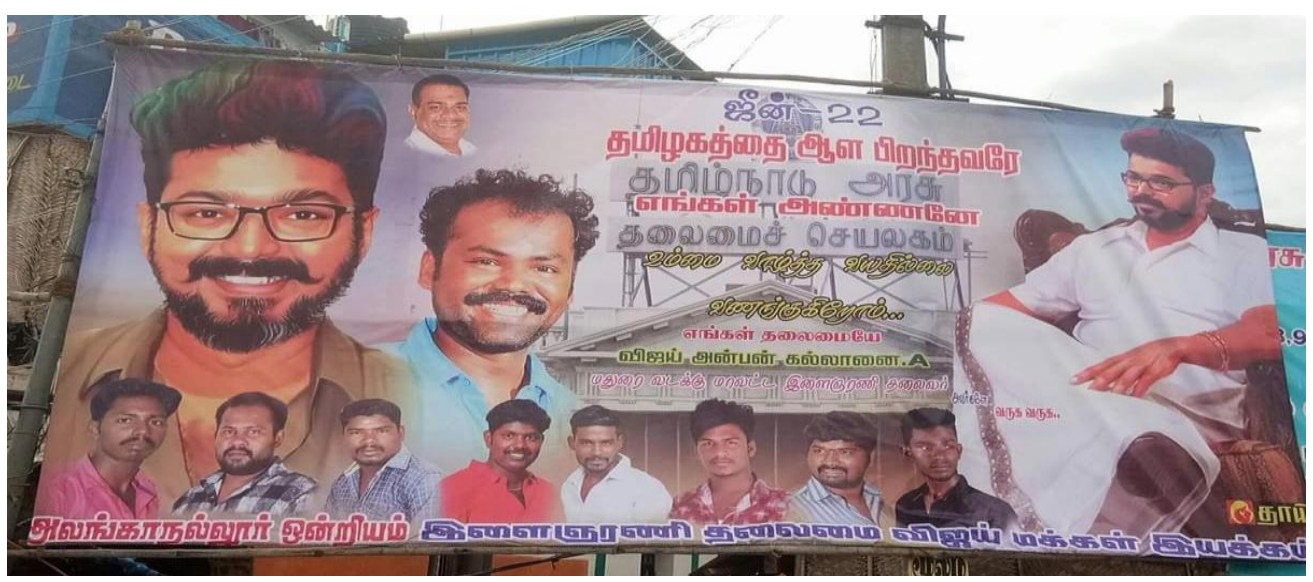

Figure5: Actor Vijay fans are celebrating his birth day in grand manner all over Tamil Nadu. This banner designed like Chief Minister of Tamil Nadu. 


\subsection{Obituary Digital Banners}

The digital banners are also designed as obituaries. One can find the obituary digital banners designed by fan clubs, youth clubs, political parties and also families. Death is also used to have many rituals and ceremonies in Tamil Nadu. The digital banners on death used to be the condolences given to the bereaved family and friends. It is also found to be reflecting the mourning of the friends and assures that the deceased would be in their remembrance. Most of the digital banners are used to be designed in black \& white and grey as these colors are considered as gloomy and miserable. The illustrations like weeping eyes used to be found in these digital banners. It denotes that the friends and families are mourning the departed soul.

\section{DISCUSSION AND CONCLUSION}

As per Walter Benjamin's work of art in the age of mechanical production loses the sense of aura, here too in the case of digital banners the art lost its aura and it leads to mass consumption. This loss of aura has the potential to open up the politicization of art, whether or not that opening is detrimental or beneficial is yet to be determined. Once the hoardings and cut outs are produced only by film producers, theatre owners and political parties, but the digital banners has opened up a democratic space and there is a mass consumption of digital banners by subalterns.

The youth have been using these digital banners for their self-publicity and promotion. As it is very difficult for a common person to get space in the visual media of Tamil Nadu, the common man has access and freedom to use the digital banners. The data collection reveals that the upper castes rarely assert their caste identity through the digital banners. As the mainstream media celebrates the upper caste culture, they don't feel the urge to celebrate it through the digital banners. So the digital banners can be called as subaltern media as it is mostly used by the backward, most backward and scheduled caste in Tamil Nadu.

Popular culture in the capitalist society functions like an industry in producing standardized products which produce standardized people. The digital banner designing studios and the digital banner consumers are predominantly men. Women are passive in the digital banners. The images of women are carefully chosen and scrutinized by Men. Although there are many banners with only men, hardly any banner with only women. Also the puberty function and marriages are celebration of caste culture and women are strictly controlled by caste culture.

\section{ACKNOWLEDGEMENT}

I would like to acknowledge my supervisor Dr. V. Ratnamala for her guidance and motivation, and my co- research scholars and the village people of my respective area of data collection who helped me with their valuable comments and support and to my family for their love and trust. Finally I would also like to acknowledge the journal editor and the publication house for evaluation and acceptance of my abstract.

\section{REFERENCE}

[1] Anderson, Benedict. (2006). Imagined. Communities:Reflections on the Origin and Spread of Nationalism. New York: Verso.

[2] Arnheim, Rudolf. (1969). Visual Thinkink. California: University of California Press.

[3] Banks, Marcus. (2001). Visual Methods in Social Research. London: Sage Publications.

[4] -----. (2007). Using Visual Data in Qualitative Research. London: SAGE Publications.

[5] Caldarola, Victor J. (1985). Visual Contexts: A Photographic Research Method in Anthropology. Visual Communication , 33-53.

[6] Carey, James W. (1989). Communication as Culture: Essays on Media and Society. New York: Routledge.

[7] Chaplin, Elizabeth. (1994). Sociology and Visual Representation. London: Routledge.

[8] Downing, John D.H. (1997). Internationalizing media theory: Transition, Power, Culture. New York: Sage Publication.

[9] Gandhi, V.P. (2007). Mass Media and Communication Strategies. New Delhi: Kanishka Publication.

[10] Greenberg, J. H. (1971). Language, Culture and Communication. California: Stanford University Press.

[11] Inden, Ronald B. (1990). Imagining India.New Delhi: Oxford University Press.

[12] Jacob, Preminda. (2010). Celluloid Deities: The Visual Culture of Cinema and Politics in South India. Uninted Kingdom: Lexington Books. 
[13] Leon-Quijano, Camilo. (2017). Visual Ethnography: Tools, Archives and Research Methods, Introducation. Visual Ethinogaphy, 7-17.

[14] Panke, Tushar. (2016). Photography Visual Communication: Direcct and indirect impact on Human Communities. Scholarly research journal for Humanity Science and English Language , 4132-4137.

[15] Rekha, Murthy. (1996). Street Media: Ambient Message in an Urban Space. Comparative Media Studies, 5-127.

[16] Vaasanthi. (2008). Cut-outs, caste and cine stars: The world of Tamil politics. New Delhi: Penguin Books.

[17] Yan, F. Liu. (2014). Visual Cryptography for Image Processing and Security: Theory, Methods, and Applications. New York: Springer International Publishing.

Citation: Dr. M. Suresh, Dr. V. Ratnamala. "The Ethnography Approaches on Digital Banner Culture in Tamil Nadu, India". International Journal of Media, Journalism and Mass Communications (IJMJMC), vol 5, no. 4, 2019, pp. 24-31 doi: http:// dx.doi.org/10.20431/2455-0043.0504003

Copyright: (C) 2019 Authors. This is an open-access article distributed under the terms of the Creative Commons Attribution License, which permits unrestricted use, distribution, and reproduction in any medium, provided the original author and source are credited. 